\title{
The Social Impact Investment Race: Towards an Interpretative Framework
}

\begin{abstract}
Purpose: the aim of this paper is to develop an interpretative framework of the evolution of Social Impact Investment (SII) in different countries. SII is a strategy of asset allocation, which combines financial profitability with a measurable social and environmental impact.

Methodology: through a thematic analysis of 75 documents, i.e. reports, experts' considerations, reflections on practitioners' experience, meetings' minutes, written by the SII Taskforce of the Group of Eight and the relative National Advisory Boards, we identify the main themes connected to the topic of SII development and recognize four main elements useful to segment the market, namely information asymmetry, financial instruments, source of capital and market intermediation.
\end{abstract}

Findings: they map the ongoing practices in the Group of Eight's members and distinguish two speeds in the evolution of SII: on one hand, there is a group of road runners, which pave the way to SII and in which SII activities have being institutionalized; on the other hand, there is a wider group of chasers, where the SII infrastructures lack any systematization.

Originality: even if some authors have provided preliminary interpretations of the SII evolution, they mainly focus on national level, and do not provide any cross-countries analysis. The findings of the present work contribute to overcome the lack of evidence characterizing the SII field and the absence of comparable and consistent data at global level by filling the academic literature about SII, through a structured interpretative framework.

Keywords: impact investing, social impact investments, social finance, thematic analysis, market infrastructure.

\section{Research Paper}




\section{Introduction}

About ten years ago, many related factors triggered some innovations in the social finance's spectrum. Indeed, even though blended strategies of capital allocation cannot be traced back, recently the spotlight has been turned to a more proactive approach (Nicholls and Emerson, 2015). The dissatisfaction with the bad habits of the financial system, the ineffectiveness of charitable models and the inefficiency of public spending, together with the worsening of the most urgent problems of our time, called for higher effectiveness in capital allocation for the provision of social services. That is how some pioneering foundations and financial intermediaries (Höchstädter and Scheck, 2015) started to envision what is now labelled as Social Impact Investment (SII). SII is a strategy of asset allocation to intentionally finance projects that combine a measurable social and environmental impact with economic sustainability and financial returns (Clarkin and Cangioni, 2015; Oleksiak, Nicholls, and Emerson, 2015). SII has its place within the social finance spectrum, distinguished by three features: firstly, social and environmental returns are not incidental, but a priori defined and ex post measured; secondly, proactive approach is used in the search of social impact (Ngoasong, Paton, and Korda, 2015); thirdly, the expectation of at least the repayment of the capital sets it apart from philanthropic activities (Nicholls and Emerson, 2015). SII is different and narrow than the broad notion of social investment intended as new paradigm for social policies rooted in the neoliberal discourse (Kersbergen, and Hemerijck, 2012); thus, scholars have added the term impact to distinguish it and stress the primacy of the social mission as investors' motivation (Daggers and Nicholls, 2016). Therefore, under the label of SII scholars include all investments made through private equity, debt, guarantees, deposits and new innovative instruments in organizations (no matter the legal form they have), funds and public equities market - based both in developed and developing countries and operating in different sectors 
- where the investors' overarching motivation is the achievement of a social impact (Höchstädter and Scheck, 2015).

Begun as some isolated and uncoordinated experimentations, SII is gradually evolving and sometimes it is even pinpointed as a market niche. Despite the interest around SII, so far the phenomenon has been discussed mainly by practitioners, with the resulting prevalence of storytelling and anecdotal narrative (Daggers and Nicholls, 2016; Hazenberg, Seddon, and Denny, 2014). SIIs suffer of a lack of a methodologically structured and comprehensive framework able to identify the infrastructure of this market, i.e. the underpinning facilities to let the system works. This absence of clarity and the limited interpretative potential of the existing literature make it challenging to analyze effectively the evolving SII practices across countries.

Thus, there is sufficient room to perform more rigorous and objective analyses about how SII has evolved worldwide. Daggers and Nicholls (2016) identify the main areas that deserve academic research: data and transparency, role of government and fields' segmentation. The latter is the wider realm to be explored because segmenting the domain according to different perspectives enables to identify different practices, trends, and needs and enhances the knowledge of the market. Moving from these gaps, our objective is to develop an interpretative framework of the cross-countries SII evolution. The framework helps to structure the description of how the essential facilities of SII market are shaped in practice and their implications on the growth of the market.

In order to achieve this objective, we perform a thematic analysis. Indeed, the thematic analysis is a flexible as well as powerful method to interpret a phenomenon by comparing and contrasting practices across different segments, geographies or stakeholders (Ngoasong, 2014; Zilber, 2007). Easily, themes work as organizing principles, which help to give a structure to the narratives and interpret how people construct and understand a phenomenon (Zilber, 2007; 
Attride-Stirling, 2001). We analyzed the documents written by the G8 SII Taskforce and its National Advisory Boards. They consist of reports including experts' considerations, reflections on practitioners' experience and meetings' minutes. Started in 2014, the work of the G8 SII Taskforce has connected hundreds of prominent experts and players in the field and has stimulated an organic thought around the topic, flown into several regional and international reports which, at now, represent the most comprehensive picture of the SII ecosystem worldwide.

The rest of the paper is articulated as follows. First, we present the theoretical lens that drove our analysis; thus, we illustrate the methodology adopted and outline the results of the thematic analysis. Then, we discuss the results and conclude with some final remarks.

\section{Infrastructural elements in social finance's evolution}

The literature review was conducted analyzing the academic works on SII identified by Daggers and Nicholls (2016) and enlarging their list through a snowball approach and a replication strategy focused on years 2015 and 2016.

The academic research about SII is concentrated in about 50 published works (Daggers and Nicholls, 2016). Some of them focus on real-word examples to study the functioning of specific financial instruments (Warner, 2013; Joy and Shields, 2013; Sinclair, Roy Huckfield and Donaldson, 2013; Jackson, 2013; Nicholls \& Tomkinson, 2015a; Stoezs, 2014; Arena, Bengo, Calderini and Chiodo, 2016), barriers to SII (Nicholls, 2010; Glanzel and Scheuerle, 2016; Mendell and Barbosa, 2013; Schwartz, Jones and Nicholls, 2015; Ormiston, Charlton, Donald and Seymour, 2015) and public policies for SII (Andion, Becker and Victor, 2012; Wells, 2012; Wood, Thornley and Grace, 2013; Addis, 2015; Spear, Paton and Nicholls, 2015; Hazenberg et al., 2014). Other authors offer a mathematical modelling (Brandstetter and Lehner, 2015; Nicholls and Tomkinson, 2015b; Nicholls and Patton, 2015; Chowdhry, Davies and Waters, 2015). Few of them propose a theoretical conceptualization of the SII phenomenon (Nicholls, 
2010; Bell and Haugh, 2015; Ormiston et al., 2015; Lyons and Kickul, 2013; Hebb, 2013; Mulgan, 2015; Oleksiak et al., 2015; Geobey, Westley and Weber, 2012; Moore, Westley and Nicholls, 2012; Young, 2015). The opinion of the authors is that a very comprehensive and detailed analytical framework has been provided by Schwartz et al. (2015). They highlight the need to build an intellectual groundwork to develop the SII field. It encompasses the generation of new ideas and the dissemination of new models and success stories, sectorial networking, grey research and also the engagement of academic institutions in the field. Besides these activities, the authors also identify three main infrastructures. They are defined not as physical systems, but more in general as the facilities that should be considered to grow the SII marketplace and let it function, such as regulations, standards, or transactional channels. The first one is the governmental infrastructure. Governments have several options to enable the SII development. To this aim, governments can act as market's regulators or facilitators (Addis, 2015; OECD, 2015). On the regulative floor, the states can support the growth of the market's demand and the fundraising activities (Schwartz et al., 2015; Oleksiak et al., 2015; Grieco, 2015; Ormiston et al., 2015), or release legal constraints to favor the flow of money into the sector (Schwartz et al., 2015). In addition, governments can be themselves social impact investors (Addis, 2015; Steinberg, 2015; Wells, 2012) by directly investing into social enterprises, by giving up a revenues' quota, for example in terms of tax incentives and fiscal policies, or by preferring social providers during the procurement procedures (Addis, 2015; Schwartz et al., 2015; Spear, 2015; Oleksiak et al., 2015; Grieco, 2015).

The second element is the facilitative infrastructure. It is devoted to connecting parties and ensure they are ready to receive or undertake SII. Much of this relates to the activity carried on by generalist professionals, service firms, or specialized consultancies (Schwartz et al., 2015). Indeed, the standing literature remarks that there is still a lack of infrastructures in terms of instruments and advisers (Glanzel and Scheuerle, 2016; Hazenberg et al., 2014; Mendell and 
Barbosa, 2013). Also social impact assessment and reporting is included in this pillar (Schwartz et al., 2015; Addis, 2015; Clarkin and Cangioni, 2015; Mendell and Barbosa, 2013; Oleksiak et al., 2015; Ormiston et al., 2015). In particular, investors need methods and metrics to measure the social performance of the investment and evaluate the social risk to build their portfolio (Mendell and Barbosa, 2013). These factors are relevant to the SII development because they affect the level of transaction costs and limits the entrance to the market.

Transaction costs will remain high until the transactional infrastructure - the third element- will be established (Schwartz et al., 2015). In terms of source of capital, organizations devoted to support social initiatives can be charitable trusts, foundations, development banks and HNWIs (Nicholls and Emerson, 2015; Ormiston, Charlton, Donald, and Seymour, 2015), but also SII funds and institutional investors (Glanzel and Scheuerle, 2016; Ormiston et al., 2015; Brandstetter and Lehner, 2015; Oleksiak et al., 2015), retail investors (Lehner and Nicholls, 2014; Nicholls and Emerson, 2015), or financial institutions and investment banks (Schwartz et al., 2015). In terms of source of after-market liquidity, innovative financial products should be structured and exit opportunities provided, whilst at the moment exit strategies and portfolio management options are very limited (Addis, 2015; Mendell and Barbosa, 2013; Schwartz et al., 2015).

Some authors provide interesting preliminary insights about how the presence or absence of the three infrastructures have helped the evolution of SII. Michelucci (2016) considers the Italian case with the aim to study how SII has developed and the roles that organizations can play to build these market infrastructures. Also other authors have already considered the progress of SII industry in specific countries, i.e. Thillai Rajan, Koserwal and Keerthana (2014) provides a perspective of SII in India, Glanzel and Scheuerle (2016) discuss impediments of SII considering the German case, Andion et al. (2012) discuss the SII infrastructures in the Brazilian case, while Kromminga (2016) studies the evolution of SII in Germany and makes a 
comparison with the UK. However, these studies mainly focus on national level, and do not offer any systemic examination nor segmentations of the SII evolution, leading to the aim of our study.

\section{Methods}

This paper is based on a thematic analysis (Marshall and Rossman, 1999) of the documents written by the G8 Social Impact Investment Taskforce and its National Advisory Boards during the period 2014-2016. In June 2013 during the UK's presidency of the G8, Prime Minister David Cameron announced the launch of an independent Taskforce aiming at "catalysing $a$ global market in impact investment in order to improve society". It has engaged more than 200 people across seven countries (UK, Canada, France, Germany, Italy, Japan, US), plus the European Commission. They were representatives from the social sector, private sector, government officials, representative of development finance institutions as well as mainstream financial institutions, academia, and Australia and OECD as observers. The group was organized into National Advisory Boards (NABs), composed by domestic members from within each country, and Working Groups (WG), focused on specific topics, namely impact measurement, asset allocation, mission alignment and international development. Both NABs and WGs, during their works, wrote several documents and, in September 2014, published some final reports. These documents represent the result of a collective effort to depict the most comprehensive picture of SII worldwide. At now, the Taskforce has been transformed into the Global Steering Group (GSG) on Social Impact Investments, with the function to monitor the implementation of the Taskforce's recommendations. This transition has entailed the entrance of new countries in the membership, namely Brazil, Israel, India, Portugal and Mexico.

The thematic analysis is the structuring and interpretation of collected data in principal concepts, by the identification of prominent or recurrent themes. A theme represents a pattern or meaning within data, which captures something important in relation to the overall research 
question (Braun and Clarke, 2006; Dixon-Woods, Agarwal, Jones, Young, and Sutton, 2005). Thus, the thematic analysis is an accessible and theoretically-flexible approach to map an intellectual field into major themes and sub-themes (Attride-Stirling, 2001; Braun and Clarke, 2006; Jones, Coviello, and Tang, 2011). We rely on the protocol of Marshall and Rossman (1999), to increase the consistency and reliability of the study. First, 75 documents were collected and organized in the classification matrix reported in the following Table 1, depending on their type and geographical focus.

[Table 1 near here]

The type was one among the following four: report produced by the National Advisory Boards (NAB) or its Working Groups (WGs); state of the art of SII diffusion country by country; recommendations' trackers of the status of application of G8 Taskforce's advices; minutes of G8 Taskforce's meetings. The geographical focus was local if documents mainly refer to a special geographic area, or global if they analyze the SII phenomenon worldwide. After the documents' classification, we started the analysis driven by the framework developed by Schwartz et al.'s (2015) illustrated in the previous section. We use the different market infrastructures as the base for the generation of the categories. Thus, documents were coded through the software NVivo.

The coding process consisted in a double reading. First, we did a literal reading to have a picture about the overall content and how SII practices are described in the documents under analysis (Ngoasong, 2014). Then, we started a coding reading: data were reduced through the coding framework illustrated in section 2 (Attride-Stirling, 2001). After that, we contrasted and compared the pieces of coded text, looking for common patterns, repeated and emphasized concepts and synonymous (Ngoasong, 2014; Burnard, Gil, Stewart, Treasure \& Chadwick, 2008; Lieblich, Tuval-Mashiach \& Zilber, 1998). As we recognized salient, common and significant arguments, we summarized them in more abstract principles, which represent the 
overreaching themes (Attride-Stirling, 2001; Burnard et al., 2008; Zilber, 2007). The table in Appendix shows the process from the creation of categories to the synthetization of themes. The "keyness" of a theme depends on its pertinence with the research question and objectives, the number of different documents in which the theme is articulated, the occurrences of the concepts, and the emphasis put on them (Braun and Clarke, 2006). Finally, the resulting themes were reiteratively refined, to accommodate new arguments and obtain discrete, specific and non-repetitive themes, which are abstracted enough to cluster the coded text segments (AttrideStirling, 2001). We validated our results by working separately, comparing our coding and discussing discrepancies. Finally, we triangulated the results with the standing theory.

\section{Results}

During the analysis, six main themes were identified. They are presented in this paragraph according to the theoretical framework of Schwartz et al. (2015), which drove us during the analysis. The different initiatives and players that we report have been identified within the coded documents and help us to describe the different themes.

\subsection{Government infrastructure}

This first infrastructure refers to the instruments available to governments to support the SII development. SII Stakeholders agreed that "government had a fundamental role in creating an enabling environment" and "government leadership and even relatively modest and targeted policy initiatives (often re-purposing existing spending) can play a positive role catalysing market activity" (G8 International Report). Specifically, they highlight the need of "state supported SII funds, perhaps with a regional focus" and to "address legislative and policy barriers" (G8 Explanatory notes for Governments). Therefore, two main themes allow to assess the evolution of SII: market regulation and public financing.

In terms of regulation, some governments have reviewed the legal definition of social businesses. Israel and Canada defined the requisites to be a social business; Italy introduced 
the B-corporation as a legal form and the Social Enterprise reform is a few steps from the approval; Japan approved the "Local Management Company" status. On the supply side, in France, according to the 90/10 Rule pension funds can invest into funds that allocate the 5$10 \%$ of their capital to social enterprises, while the Portuguese government passed the new regulation for social entrepreneurship investment funds. However, besides these isolated examples, our analysis reveals that the countries under the lens suffer of a lack of systematic regulatory framework able to incentivize SIIs. Moderately different are the cases of UK and US. In UK, the Cabinet Office approved several pieces of legislation related to SII: the Social Investment Tax Relief, the Dormant Account Act, the Social Value Act, the Community Investment Tax Relief, the review of intermediaries' fiduciary duties. Similarly, the US Congress clarified the pension funds' fiduciary duties by updating the Employee Retirement Income Security Act (ERISA), approved the New Market Tax Credit and the legislation about new social enterprises' corporate form passed in several states.

In terms of public financing, the analysis acknowledges the effort of lobbing governments to channel public funds into the sector. In some cases, this fact has driven governments to commit grants and catalytic capital to SII, with the aim to match private investments and assume first loss layers’ positions. In Japan, the New Public Initiative committed \$86 million to social startups; in Israel, the government co-funded two SII funds; in Canada, the Quebec government coinvested into the Chantier de l'Economie Sociale; the Portuguese government approved the Portugal Innovacao Social program. Other countries, such as Italy and Mexico, are even behind. On the contrary, in UK the supply of capital for SII is heavily dominated by the public sphere. As a matter of fact, the Investment Readiness Programme allocated $£ 20$ million to SII, half to the Investment and Contract Readiness Fund and the other half to the Social Incubator Fund. The Social Outcome Fund and the Big Lottery Fund are other examples which support this result. Our analysis shows that in the case of UK, the government invested also indirectly 
through Big Society Capital, a wholesaler established from the enactment of the regulation on the use of unclaimed assets. Similarly, also in US, both at central as well as federal level, several funds have been approved, such as the SII Small Business Investment Company Initiative, the Nonprofit Finance Fund, and the Federal Social Innovation Fund.

Finally, some of the analyzed governments, namely UK, US, Israel, Portugal, Germany, Mexico, Canada, and Australia, have financed the growth of the SII market using their purchasing's power. They have experimented pay for success schemes, a form of contract where the buyer pays for achieved social outcomes rather than for produced outputs. Especially the UK and US are where more sophisticated schemes, such as social impact bonds, have been experimented firstly and mostly.

\subsection{Facilitative infrastructure}

The facilitative infrastructure refers to the services required to ensure the social investees and investors readiness. It includes the facilities in the space of counselling and incubation, which help social organizations to consolidate their business models and showcase their impact. It is acknowledged that "only a small share [of social organizations] is currently in a position to record its impact and utilise the results as a steering instrument". The Working Group on International Development suggests "that grant and investment resources [...] should be used to provide direct support to bolster the growth of local intermediaries and companies".

According to our results, SII deals lack reliable track-records. The theme of information asymmetry frequently recurred in the documents and was mentioned among those elements that influences the market development. The Canadian report claims that "the limited track record of impact investment opportunities has deterred some investors" and "there remains a lack of comprehensive and fundamental empirical knowledge that can satisfy the needs of social investors" according to the German report. Indeed, when knowledge is limited and statistics do not favor the decision process, investors are dissuaded from taking the first mover risk. Results demonstrate that there is a growing development of impact measurement systems 
and metrics such as the Global Reporting Initiative (GRI), or repository of indicators such as the Impact Reporting and Investment Standards (IRIS), the Global Value Exchange Initiative, and the GIIRS, or proprietary measurement tools and methodological approaches. Australian experts states that "work is underway around the globe to map and build the baseline data and investment benchmarks that are needed for institutional investors to assess performance of impact investment products and make allocations that integrate risk, return and impact." However, seldom they are used to track investments' results and even more rarely to make cross-country comparisons. Moreover, the approach varies by countries. In some cases, such as Australia, Japan, Portugal, US, Germany, France there is the tendency to converge toward "standards and guidelines for social impact measurement and reporting", while in other cases the NABs recommended to develop a methodological approach rather than a standard, in order to guarantee flexibility and a certain degree of comparability between deals, or to delegate the function to a third-party certification system. Whatever the approach, at present, no single measurement system has reached the critical mass to be considered a standard; thus, in this fluid phase, there is a variety of tools on paper, which are sporadically used in practice.

\subsection{Transactional infrastructure}

The transactional pillar refers to the infrastructure needed to lower transaction costs, thus source of capital for SII, but also the activities done by financial intermediaries and the investment instruments (Schwartz et al., 2015). "SII market appears highly disconnected and different types of intermediaries are needed to developing new ways of financing social organizations" (UK Report). Our analysis identified three themes which resulted to be important in the SII development.

First, private capitals. "Impact investment is emerging from existing institutional contexts including established capital markets and philanthropic traditions" (Australia Report). The results show that private investors are mainly well established organizations with philanthropic mission. Foundations and charities resulted to play a pioneering role in developing the SII 
market, especially in US and UK. Here, some remarkable examples are the Bill and Melinda Gates Foundation and the MacArthur Foundation in US, Esmée Fairbairn Foundation in UK, the Rockefeller Foundation both in US and UK. Even if public funding is very limited, it still represents the main source of capital. Institutional investors, such as insurance companies or pension funds, still remain at the margin, both for skepticism and legal uncertainty.

"Pension and life insurance funds are already considered to be two of the most important sources for socially responsible investments in a wider sense. However, the strict regulation faced by these entities [...] represents a great challenge with regard to involvement in SII." (German Report). In US, the new guidance on the Employee Retirement Income Security Act (ERISA) admits that private pension funds consider environmental, social, and governance factors in the investment decisions.

Also investments from retail customers are very rare. Seldom they directly invest into social recipients nor retail banks manage SII products. However, the retail segment emerged as a potential source of capital and tailored vehicles or products, for example "France is also the only country in the world that has a sector for solidarity-based financing by individuals (general public), underpinned by individual and collective employee savings schemes (company savings plans)" or community shares in Japan and UK, are attracting a lot of interest. In Portugal, the Portuguese Financial Service Authority allowed non-qualified retail investors to invest their capital in the European Social Enterprise funds, even if with some limitations.

Second, private intermediation. Our analysis reveals that commercial and investments banks as well as specialized financial intermediaries and advisers offer products or services targeted to social enterprises. Alternatively, they manage funds set with philanthropic or public capitals, which invest in social recipients. In Italy, France, Australia, Canada and Portugal some specialized and generalist banks manage tailored loan-based products for social enterprises. Results shows that the specialization of intermediaries is significant especially in UK and US. 
In UK, relevant examples are Bridges Ventures, Nesta, ClearlySo, Social Finance, Big Issue Investment, Triodos Bank. In US large financial institutions such as Goldman Sachs, Deutsche Bank, Morgan Stanley and J.P. Morgan have set SII funds and SII advisers have been born, such as Social Finance US and Imprint Capital.

Finally, financial instruments. The results present a quite homogeneous picture. Investments usually take the form of loan or venture philanthropy. Specialized and commercial banks, foundations and charities are slowly experimenting forms of venture philanthropy directed to social recipients. Indeed, the examination displays that SII are usually identified as venture capital initiatives focused on social-like sectors. Moreover, also examples of bonds-like instruments proliferate: community bonds in Canada, social impact securities in France, social bonds in Italy, saving bonds in Germany. They are usually bonds issued by organizations to finance special social programs. Sometimes they are charitable bonds, when the issuer devolves a part of the raised capital to social organizations.

\section{An interpretative framework of SII evolution}

The results of this paper, whose aim is to develop an interpretative framework of SII evolution at the global level, come out from a thematic analysis of 75 documents. They consist of reports including experts' considerations, reflections on practitioners' experience and meetings' minutes. Documents were selected because they resulted from the effort of hundreds of experts coming from different professional areas and depict the most comprehensive information about the state of evolution of SII in twelve countries worldwide. The use of thematic analysis was coherent with our objective to identify the main themes related to the SII market development and identify analogies and differences in the way countries face them. Indeed, our investigation unveils many signals of an increased advancement of the SII market in terms of general interest from investors and economic value of the initiatives, however, they are countervailed by a significant prudence and heterogeneity in instruments and approaches. We isolated six themes, 
which can be useful to draw an interpretative framework of the SII advancement, namely: market regulation, public financing, information asymmetry, private capitals, private intermediation, financial instruments. Concerning the government infrastructure, which refers the instruments available to governments to support the SII development, we identified the themes market regulation and public financing; as for the services required to ensure the social investees and investors readiness, i.e. the facilitative infrastructure, the two themes emerged from the analysis are information asymmetry and private intermediations. Lastly, the themes private capitals and financial instruments are related to the infrastructure needed to lower transaction costs, thus source of capital for SII, labelled as transactional infrastructure.

With regard to information asymmetry and financial instruments, the countries under the lens present a similar progress. On the front of information asymmetry, accordingly to literature (Arena, Azzone, Begno and Calderini, 2016), the analysis enlightened a wide variety of measurement tools to assess the performance of the investment, usually developed ad hoc by both investors and public bodies. However, at this stage, there is a general lack of a homogenization and reconciliation among these metrics. Besides the problem of defining measurement technicalities, the ulterior open issue is the definition of governance models able to ensure reliability, accountability and liability to any transaction in the SII market. This also means that the measurement standards could be intended as emergent properties of the market rather than standards imposed through a top-down, de-jure approach.

On the front of financial instruments, the general approach common to all the countries is a prudential preference for debt-like instruments and debt-based venture philanthropy, generally mixed with grants. This fact confirms the idea that charitable trusts and foundations' capitals are the money able to activate the market (Nicholls and Emerson, 2015; Ormiston et al., 2015), but also dispels the myth of SII as a result of sophisticated financial engineering (Mendell and 
Barbosa, 2013; Schwartz et al., 2015). Thus, SII worldwide has ambitious goals in theory, but, in practice, it is still biased toward grant making in the social finance spectrum.

With regard to the other four themes identified in this paper, they paint a more heterogeneous state of development of SII in different contexts. Coherently with the previous result, private capitals come mainly from charities and foundations. Especially in UK and US they have played a catalytic role and their presence in the SII ecosystem is well established. On the contrary, institutional investors, such as pension funds and insurance companies, are still looking from a distance, whereas high net worth individuals are still reluctant to massively engage in this new market. Thus, in spite of an ever increasing number of private initiatives supporting pilot projects and experimentations, the market is still far from reaching the critical mass needed to trigger the definitive consolidation of SII as a new asset class. The lack of large scale private initiatives is only partially compensated by public policy initiatives, notwithstanding the relatively high degree of attention that most governments are paying to SII (Addis, 2015; Schwartz et al., 2015; Oleksiak et al., 2015; Steinberg, 2015). Public support is articulated in many different forms but still confined to prototypes and small scale initiatives, with the sole exception of US and UK. Indeed, here, public SII programs have overtaken the experimental dimension and they result from a more systematic and strategic approach to this form of investment. Thus, the source of capital is a useful perspective from which to interpret the SII evolution. The following matrix resumes the evolution of SII sources of capitals in the G8 countries (Table 2):

\section{[Table 2 near here]}

Finally, the remaining two themes assess the stage of development in terms of types of market intermediation. With this term, we refer to the intermediary's activities that help to low transaction costs, reduce the legal uncertainty in the market and connect investors and recipients. The results showed that smart regulation has not been an established issue on the 
political agendas yet. Worldwide governments are still very cautious in endorsing the SII market development, whilst it would benefit from a public intervention directed to lower the level of risks and provide capacity building funds. The sole exception is represented by UK and US where several reforms and acts have been approved as also emerged from the literature (Oleksiak et al., 2015; Addis, 2015). Again, market regulation allows to distinguish those markets with advanced practices from the countries where only some solitary pieces of legislations have passed. Besides public regulation, also private intermediation resulted to be a relevant element to segment the field. Specialized and commercial banks have tailored products and services to answer to the needs of social enterprises. They have the form of loans, guarantees schemes, soft or peer lending and affordable mortgages. Moreover, in UK and US, there is an increasing specialization of advisers and intermediaries and the entrance of investment banks in this space. The following matrix (Table 3) maps different stage of progress in relation to market intermediation:

[Table 3 near here]

\section{Conclusions}

Moving from the themes identified during the analysis, this paper has drawn an interpretative framework to evaluate the SII evolution by comparing the industry's progress in different countries. We have used the concept of infrastructure to identify the facilities needed to let the market grow and then we have isolated six themes that refer to those facilities. These themes are the dimensions of the interpretative framework resulted from the analysis. Considering how these dimensions translate differently in the countries included in the analysis, we have been able to assess the evolution of the SII market. 
Indeed, the existing academic studies frequently use case-studies and success stories to describe the SII practices ongoing worldwide, but this narrative approach suffers of a limited interpretative potential (Daggers and Nicholls, 2016). The suggested interpretative framework offers some analytical dimension along which analyzing the evolving practices associated with SII. It is based on four elements, namely information asymmetry, financial instruments, source of capital and market intermediation. Within each of these aspects, it has classified the SII practices according to their degree of development: experimental (if there SII are sporadic and occasional) or systematic (if SII has been institutionalized into the strategy of market actors). A representation of the framework is provided in Table 4.

[Table 4 near here]

The resulting picture of this paper confirms that SII is still a small market niche, which wakes up a significant level of interest, at least at an intellectual and theoretical level. Considering the different configurations of the SII market that the theme identifies, the framework pinpoints two intensities characterizing the development of SII market. Specifically, there is a small group of road runner countries. Here, the market has overcome the experimental dimension and moved toward a more systemic approach. Although, information asymmetry together with illiquidity of investments still struggle SII, multiple sources of capitals are committed to the practice: both privates and governments channel capitals toward SII. Furthermore, several SII have been financed by governments, which has played a key role in setting SII funds and in providing catalytic resources. Consequently, thanks to the double commitment of public and private sector, the amount of capitals channeled in the market is higher. Lastly, both market regulation and private intermediation have set the bases to build a solid market infrastructure. Indeed, in this group of road runners countries there is an organic legal framework that favors SII and investment banks and intermediaries specialize in SII and set SII funds. 
The vast majority of the analyzed cases, instead, have been classified as chasers. In these countries, SII are mainly low-risky experimentations, infrequently done by public or the private investors, and the bases for the regulative and transactional infrastructures have to be posed. Therefore, within this second group, the practices are still at an experimental dimension, to prove SII feasibility and functioning: the approach is that of setting small and low-risky pilots to test instruments, logics, and methods. However, in some countries the public sector skeptically steps in and the initiative is left mainly to private organizations. In the few other cases where public commitment is present, it is still low compared to the first group, and also private investors sporadically offer services and products to social enterprises. In these countries, the regulation is vacant and intermediation manly consist in affordable, customtailored products offered by commercial banks to their social business clients.

Lastly, our results show that both groups share the problems related to the accounting tools and, thus, the absence of track records characterizes the entire market. In the same way, a general caution prevails worldwide, due to the illiquidity of SII and the most diffused instruments are debt or philanthropic based.

These results are obtained through a thematic analysis. Sometimes, the thematic analysis is criticized for the subjectivity of interpretations and lack of rigor. However, we adopted some precautions in order to be rigorous: we organized the documents in a classification matrix, coded them separately, discussed divergences and discrepancies, and triangulated different types of documents. However, all the documents were authored by G8 SII Taskforce and its National Advisory Boards. This could appear as a bias in data, for the focus and aim of the working groups, but it is worth to be specified that the roundtables were attended by hundreds of experts, which brought to the table a variety of perspectives, practices and geographies, so that they represent a rich and variegate picture of SII worldwide. 
Our interpretative framework has implications for academics and practitioners. Practically, the four elements helped us to sort the degree of advancement of SII practices in several countries. They drew a picture about the state of the art about SII in the different nations under the lens, and identified a small group of road runner countries versus a larger group of chasers. Moreover, the merit of this paper is to identify the factors that played a crucial role in the road runner countries, posing the basis for further investigations about if and how these factors evolve overtime, how their influence on SII evolution can change, and their impact on economic values and volumes of SII transactions. The proposed framework is also a supportive instrument to examine the SII diffusion outside the 12 countries under the lens, because it identifies the fundamental discriminant elements to be taken into the analysis.

From an academic point of view, this paper answers to the call of Daggers and Nicholls (2016) for segmentation of the field, and identifies four elements that could be useful to classify the different SII practices worldwide. The findings of the present work contribute to overcome the storytelling approach characterizing the SII field and the absence of comparable and consistent data at global level by filling the academic literature about SII, through a structured interpretative framework. In addition, the results put light on the role played by the public sector, in terms of the effectiveness of public incentives, impact of SII public policies and selfsustainability of SII, but also open the road to further investigate how the policy vacuum is used in the chaser countries where the public sector still looks at the SII practices from a distance. Moreover, the case-study approach could further test the validity of the framework and identify additional elements, which are relevant when assessing the development of SII practices in different institutional contexts. Indeed, the role played by cultural factors, socioeconomic development, value systems, history, and path dependency are other factors that could potentially affect the evolution of the SII marketplace. Finally, it prepares the ground to investigate how private and public source of capital, regulation and market intermediation, are 
connected to the market performances and if the absence of these enablers hampers the development of the SII market or not.

\section{References}

Addis, R. (2015), The roles of government and policy in social finance, in Nicholls, A., Paton, R., \& Emerson, J. (Eds.), Social Finance, Oxford University Press, Oxford, UK, pp. 383459.

Andion, C., Becker, Y., \& Victor, I. (2012), "Is private social investment a form of public goods coproduction? An overview of the Brazilian reality", Annals of Public and Cooperative Economics, Vol. 83 No. 3, pp. 407- 433.

Arena, M., Azzone, G., Bengo, I., Calderini, M. (2016). "Indicators and metrics for social business: A review of current approaches", Journal of Social Entrepreneurship, Vol. 7 No. 1, pp. 1-24.

Arena, M., Bengo, I., Calderini, M., \& Chiodo, V. (2016), "Social Impact Bonds: Blockbuster or Flash in a Pan?", International Journal of Public Administration, doi: 10.1080/01900692.2015.1057852.

Attride-Stirling, J. (2001), "Thematic networks: an analytic tool for qualitative research", Qualitative research, Vol. 1 No. 3, pp. 385-405.

Bell, B. \& Haugh, H. (2015), “Exploring Institutional Field Emergence: Insights from Social Investment", paper presented at SSFII Conference Oxford, 23-25 April 2015, Oxford, UK.

Brandstetter, L. \& Lehner, O., M. (2015), “Opening the Market for Impact Investments: The Need for Adapted Portfolio Tools”, Entrepreneurship Research Journal, Vol. 5 No. 2 , pp. 87-107.

Braun, V. \& Clarke, V. (2006), "Using thematic analysis in psychology”, Qualitative Research in Psychology, Vol. 3 No. 2, pp. 77-101. 
Brunard, P., Gil, P., Stewart, K., Treasure, E. \& Chadwick, B. (2008), “Analysing and presenting qualitative data”, British Dental Journal, Vol. 204 No. 8, pp. 429-432.

Chowdhry, B., Davies, S. W., \& Waters, B. (2015), “Incentivizing Impact Investing”, Working Paper, UCLA Anderson School of Management, Los Angeles, CA, available at http://www.anderson.ucla.edu/faculty/bhagwan.chowdhry/iii.pdf (accessed September 2016).

Clarkin, J. E., \& L. Cangioni, C. (2015), "Impact Investing: A Primer and Review of the Literature”, Entrepreneurship Research Journal, Vol. 6 No. 2, pp. 135-173.

Daggers, J. \& Nicholls, A. (2016), “The Landscape of Social Impact Investment Research: Trends and Opportunities", University of Oxford, Oxford, UK, available at http://www.sbs.ox.ac.uk/sites/default/files/research-projects/CRESSI/docs/thelandscape-of-social-impact-investment-research.pdf (accessed September 2016).

Dixon-Woods, M., Agarwal, S., Jones, D., Young, B., \& Sutton, A. (2005), “Synthesizing qualitative and quantitative evidence: a review of possible methods", Journal of health services research \& policy, Vol. 10 No. 1, pp. 45-53.

Geobey, S., Westley, F. R., \& Weber, O. (2012), "Enabling Social Innovation through Developmental Social Finance", Journal of Social Entrepreneurship, Vol. 3 No. 2, pp. $151-165$.

Glanzel, G. \& Scheuerle, T. (2016) “Social Impact Investing in Germany: Current Impediments from Investors' and Social Entrepreneurs' Perspectives", VOLUNTAS: International Journal of Voluntary and Nonprofit Organizations, Vol. 27 No. 4, pp. 1638-1668.

Grieco, G. (2015). Assessing Social Impact of Social Enterprises. Does One Size Really Fit All? Springer International Publishing, Switzerland. 
Hazenberg, R., Seddon, F., \& Denny, S. (2014), “Intermediary Perceptions of Investment Readiness in the UK Social Investment Market", VOLUNTAS: International Journal of Voluntary and Nonprofit Organizations, Vol. 26 No. 3, pp. 846-871.

Hebb, T. (2013), “Impact Investing and Responsible Investing: What Does It Mean?”, Journal of Sustainable Finance \& Investment, Vol. 3 No. 2, pp. 71-74.

Höchstädter, A., K. \& Scheck, B. (2015), “What’s in a Name: An Analysis of Impact Investing Understandings by Academics and Practitioners", Journal of Business Ethics, Vol. 132 No. 2, pp. 449-475.

Jackson, E. T. (2013), "Evaluating social impact bonds: Questions, challenges, innovations, and possibilities in measuring outcomes in impact investing", Community Development, Vol. 44 No. 5, pp. 608-616.

Jones, M. V., Coviello, N., \& Tang, Y. K. (2011), "International entrepreneurship research (1989-2009): a domain ontology and thematic analysis”, Journal of business venturing, Vol. 26 No. 6, pp. 632-659.

Joy, M., \& Shields, J. (2013), "Social Impact Bonds: The Next Phase of Third Sector Marketization?", Canadian Journal of Nonprofit \& Social Economy Research, Vol. 4 No. 2, pp. 39-55.

Kromminga, L. (2016), Gaps in the Impact Investment Ecosystem. Comparing the markets of Germany and UK, Anchor Academic Publishing, Hamburg, Germany.

Lehner, O., M., \& Nicholls, A. (2014), "Social Finance and Crowdfunding for Social Enterprises: a Public-Private Scheme Providing Legitimacy and Leverage”, Venture Capital: An International Journal of Entrepreneurial Finance, Vol. 16 No. 3, pp. 271286.

Lieblich, A., Tuval-Mashiach, R. \& Zilber, T. (1998), "Narrative Research: Reading, Analysis and Interpretation", SAGE Publications. 
Lyons, T. S., \& Kickul, J. R. (2013), “The Social Enterprise Financing Landscape: The Lay of the Land and New Research on the Horizon", Entrepreneurship Research Journal, Vol. 3 No. 2, pp. 147-159.

Marshall, C. \& Rossman, G. (1999), Designing Qualitative Research, 3rd ed, Sage, London, UK.

Mchugh, N., Sinclair, S., Roy, M., Huckfield, L., \& Donaldson, C. (2013), "Social impact bonds: a wolf in sheep's clothing?”, Journal of Poverty and Social Justice, Vol. 21 No. 3, pp. 247-257.

Mendell, M., \& Barbosa, E. (2013), “Impact Investing: A Preliminary Analysis of Emergent Primary and Secondary Exchange Platforms", Journal of Sustainable Finance \& Investment, Vol. 3 No. 2, pp. 111-123.

Michelucci, F.V. (2016), "Social Impact Investments: Does an Alternative to the Anglo-Saxon Paradigm Exist?", Voluntas: International Journal of Voluntary and Nonprofit Organizations, doi:10.1007/s11266-016-9783-3.

Moore, M. L., Westley, F. R., \& Nicholls, A. (2012), “The Social Finance and Social Innovation Nexus”, Journal of Social Entrepreneurship, Vol. 3 No. 2, pp. 115-32.

Mulgan, G. (2015), “Social finance: does 'investment' add value?”, in Nicholls, A., Paton, R., \& Emerson, J. (Eds.), Social Finance, Oxford University Press, Oxford, UK, pp. 45-63.

Nicholls, A. (2010), “The Institutionalization of Social Investment: The Interplay of Investment Logics and Investor Rationalities”, Journal of Social Entrepreneurship, Vol. 1 No. 1, pp. 70-100.

Nicholls, A. \& Emerson, J. (2015), “Social Finance: Capitalizing Social Impact”, in Nicholls, A., Paton, R., \& Emerson, J. (Eds.), Social Finance, Oxford University Press, Oxford, UK, pp. 207-249. 
Nicholls, A., \& Patton, A. (2015), "Projection, valuation and pricing in social finance", in Nicholls, A., Paton, R., \& Emerson, J. (Eds.), Social Finance, Oxford University Press, Oxford, UK, pp. 311-334.

Nicholls, A., \& Tomkinson, E. (2015a), “The Peterborough Pilot Social Impact Bond” in Nicholls, A., Paton, R., \& Emerson, J. (Eds.), Social Finance, Oxford University Press, Oxford, UK, pp. 335-380.

Nicholls, A., \& Tomkinson, E. (2015b). "Risk and return in social finance" in Nicholls, A., Paton, R., \& Emerson, J. (Eds.), Social Finance, Oxford University Press, Oxford, UK, pp. 282-310.

Ngoasong, M., Paton, R. \& Korda, A. (2015). Impact Investing and Inclusive Business Development in Africa: A research agenda. IKD Working Paper No. 76. Milton Keynes: The Open University.

Ngoasong, M.Z. (2014). "How international oil and gas companies respond to local content policies in petroleum-producing developing countries: a narrative enquiry", Energy Policy, Vol. 73, pp. 471- 479.

OECD. (2015), "Social Impact Investment: Building the Evidence Base”, OECD Publishing, Paris, France, available at http://www.oecd.org/publications/social-impact-investment9789264233430-en.htm (accessed June 2016).

Oleksiak, A., Nicholls, A., \& Emerson, J. (2015), “Impact investing: a market in evolution”, in Nicholls, A., Paton, R., \& Emerson, J. (Eds.), Social Finance, Oxford University Press, Oxford, UK, pp. 207-249.

Ormiston, J., Charlton, K., Donald, M. S., \& Seymour, R. G. (2015), “Overcoming the Challenges of Impact Investing: Insights from Leading Investors”, Journal of Social Entrepreneurship, Vol. 6 No. 3, pp. 352-378. 
Schwartz, R., Jones, C., \& Nicholls, N. (2015), "Building the Social Finance infrastructure", in Nicholls, A., Paton, R., \& Emerson, J. (Eds.), Social Finance, Oxford University Press, Oxford, UK, pp. 488-517.

Spear, R., Paton, R., \& Nicholls, A. (2015), "Public policy for social finance in context", in Nicholls, A., Paton, R., \& Emerson, J. (Eds.), Social Finance, Oxford University Press, Oxford, UK, pp. 460-487.

Steinberg, R. (2015), "What should social finance invest in and with whom?”, in Nicholls, A., Paton, R., \& Emerson, J. (Eds.), Social Finance, Oxford University Press, Oxford, UK, pp. 64-95.

Stoesz, D. (2014), "Evidence-Based Policy Reorganizing Social Services Through Accountable Care Organizations and Social Impact Bonds", Research on Social Work Practice, Vol. 24, No. 2, pp. 181-185.

Thillai Rajan, A., Koserwal, P., \& Keerthana, S. (2014), “The Global Epicenter of Impact Investing: An Analysis of Social Venture Investments in India”, The Journal of Private Equity, Vol. 17 No. 2, pp. 37-50.

Young, D. R. (2015), “Financing social innovation”, in Nicholls, A., Paton, R., \& Emerson, J. (Eds.), Social Finance, Oxford University Press, Oxford, UK, pp. 96-112.

Warner, M. E. (2013), "Private finance for public goods: Social impact bonds", Journal of Economic Policy Reform, Vol. 16 No. 4, pp. 303-319.

Wells, P. (2012), “Understanding Social Investment Policy: Evidence from the Evaluation of Futurebuilders in England", Voluntary Sector Review, Vol. 3 No. 2, pp. 157-77.

Wood, D., Thornley, B., \& Grace, K. (2013), “Institutional impact investing: practice and policy”, Journal of Sustainable Finance \& Investment, Vol. 3 No. 2, pp. 75-94. 
Zilber, T. M. (2007), "Stories and the Discursive Dynamics of Institutional Entrepreneurship: The Case of Israeli High-tech after the Bubble”, Organization Studies, Vol. 28 No. 7, pp. 1035-1054. 